\title{
The Stay Independent Brochure as a Screening Evaluation for Fall Risk in an Elderly Thai Population
}

This article was published in the following Dove Press journal:

Clinical Interventions in Aging

\author{
Sriprapa Loonlawong $\mathbb{B}^{1,2}$ \\ Weerawat Limroongreungrat ${ }^{3}$ \\ Wiroj Jiamjarasrangsi $\mathbb{D}^{\prime}$ \\ 'Department of Preventive and Social \\ Medicine, Faculty of Medicine, \\ Chulalongkorn University, Bangkok, \\ Thailand; ${ }^{2}$ Regional Health Promotion \\ Center 9 Nakhon Ratchasima, \\ Department of Health, Ministry of Public \\ Health, Nakhon Ratchasima, Thailand; \\ ${ }^{3}$ College of Sports Science and \\ Technology, Mahidol University, Nakhon \\ Pathom, Thailand
}

Introduction: The Stay Independent Brochure (SIB) is a widely used fall-risk selfassessment tool, which is part of the Stopping Elderly Accident, Deaths \& Injuries (STEADI) program in the US. However, the validity and reliability of the SIB have not been established in an elderly Thai population.

Objective: To construct a fall risk screening tool based on the SIB in a Thai elderly population and investigate its psychometric effect in a community context.

Methods: A total of 480 elderly participants volunteered to take part in this study from the Nakhon Ratchasima province. In the first part of the study, the original version of the SIB was translated into Thai (total 12 questions) and adapted into a modified version (total 18 questions). The translated SIBs were cross-culturally adapted and tested for content validity, test-retest reliability, inter-rater reliability, construct validity and internal consistency. In the second part of the study, the psychometric properties of the translated SIBs were assessed using test-retest and inter-rater reliability and content and construct validity.

Results: The SIBs had good content validity (IOC: 0.80 to 1.00 ), and the interclass correlation coefficient (ICC) of test-retest and inter-rater reliability was excellent for both SIB versions (ICC $0.89-0.95$ ). The construct validity of 18 questions was tested by principal component factor analysis with varimax rotation and using factor loading greater than 0.4 , and yielded 6 factors that explained 59.1\% of the variance in fall risk (more than 12 questions). The coefficient alpha was higher than the usually recommended value of 0.70 for the total score of both SIB versions. The convergent validity between the TUG and BBS tests was statistically significant $(\mathrm{p}<0.001)$.

Conclusion: Based on psychometric properties, it is recommended that the two Thai versions of the SIB are an appropriate initial screening tool for the multi-steps fall risk assessment algorithm in predicting falls in an elderly Thai community.

Keywords: Stay Independent Brochure, psychometric property, screening, falls, Thai elderly

\section{Introduction}

The worldwide population is ageing, consequently falls and resulting injuries in the elderly people are increasingly becoming a global public health concern. Approximately one-third (28-35\%) of 65-year olds fall at least once a year, with $40-60 \%$ of falls leading to injuries. ${ }^{1,2}$ In addition, falls lead to the death of more than 646,000 each year (1770 deaths per day), with over $80 \%$ occurring in low and middleincome countries. ${ }^{3}$ In Thailand, falls in the elderly people are the second leading cause of death after traffic accidents and amount to $10.6 \%$ of all deaths in this age group. ${ }^{4}$

Fall prevention plays a crucial role in reducing related injuries and premature death. Annual screening for assessing personal risks of falling, together with
Correspondence: Wiroj Jiamjarasrangsi Department of Preventive and Social Medicine, Faculty of Medicine,

Chulalongkorn University, Rama IV Road, Pathumwan, Bangkok 10330, Thailand

Tel +6622564000 Ext. 3700

Fax +6622564292

Email wjiamja@gmail.com 
appropriate risk management, has been shown to decrease fall ratio to $24 \%{ }^{5-8}$ There are several available fall risk screening methods, including, medical history questions, physical examination, comprehensive screening tools and functional fitness tests. ${ }^{9}$ However, there is no identified best single method, ${ }^{10}$ with current recommendations based on the combination of multiple methods. ${ }^{9-12}$

The fall risk screening algorithm used in the U.S. Centers for Disease Control's Stopping Elderly Accidents, Death \& Injuries (STEADI) program is one of the only few programs, which follows the multiple methods recommendation. ${ }^{13-15}$ It combines a number of screening tools in a stepwise manner, starting with a brief and simple assessment tool, the "Stay Independent Brochure" (SIB). The SIB can be easily selfadministered by elderly individuals or be conducted via frontline healthcare personnel, which can then be followed by specialized assessment procedures (Time Up and Go test (TUG), 30-Second Chair Stand, 4-Stage Balance Test), and a detailed health history and physical examination. This allows for more specialized health care for those at increased fall risk. In the U.S., the content validity and reliability of the initial SIB fall risk assessment were consistent across cultures, language, and communities ${ }^{16}$ and covered all relevant fall-related factors. ${ }^{17}$ It also satisfied concurrent validity when it was compared against the clinical evaluation of fall risk conducted by geriatricians. ${ }^{18}$ Furthermore, the adapted STEADI fall risk algorithm also had a high predictive validity for future fall risk when assessed using U.S. survey cohort data in a nationally representative sample. ${ }^{19}$ However, the validity of the SIB and the overall STEADI fall risk algorithm have never been examined outside of the U.S.A.

Since limited external validity is a central issue with falls risk screening tools when used across different populations, ${ }^{20}$ we planned to undertake a pilot study as a preparatory stage to examine the applicability of the STEADI fall risk algorithm in a Thai community. Specifically, the purpose of this report was to translate and culturally adapt the SIB in a Thai context and investigate psychometric properties, such as content and construct validity, test-retest reliability, and interrater reliability. The outcome of this study will provide a basis for further examination of the predictive validity of the STEADI fall risk algorithm in predicting falls amongst elderly Thai individuals.

\section{Materials and Methods}

This study was performed according to the Declaration of Helsinki and an approval of the Institutional Review Board of Faculty of Medicine, Chulalongkorn University (IRB
No. 532/61) was granted. All participants provided written informed consent prior to their participation. Participant identity data were kept confidential and deleted before analysis. The databases did not hold any identifiable participant data. The data were collected from October to December 2018. There were two parts of the study including: tool translation and cross-cultural adaptation process of the SIB into Thai context; and its psychometric properties testing.

Part 1: SIB translation and cross-cultural adaptation

This was conducted according to the standard guidelines using 4 stages. $^{21}$ In Step 1, upon obtaining permission from the CDC-copyright owner, the original SIB was translated into Thai by two independent linguistic specialists (T1 and T2). In Step 2, the two translated versions were then reconciled by the researchers and the two linguistic specialists into the finalized Thai draft (T12). In Step 3, this finalized draft was then back-translated into English by another two independent linguistic specialists who were unaware of the original SIB (BT1 and BT2). In Step 4 of the expert committee review, all documents including Forward translation (T1 and T2), Thai Draft 1 (T12), and Backward translation (BT1 and BT2) were submitted to a committee of three health experts (a physician, nurse, and physical therapist practicing in the field of elderly care) for the comparison and reconciliation (both languages and cultures) into the finalized Thai Draft 2.

Part 2: Psychometric properties testing

\section{Population and Sample Group}

The target population were individuals aged 65 yrs or older living in the Nakhon Ratchasima Province. The inclusion criteria required the participants to be able to communicate in Thai, and be free from hearing impairment and dementia, as assessed by the Mini Mental State Examination Thai version (MMSE-Thai 2002). ${ }^{22}$ A sample size of 50 was considered appropriate for the inter-rater and intra-rater reliability study, ${ }^{23}$ however the proper size for construct validity should be 10-20 times bigger than the number of questions. ${ }^{24}$ Since the Thai SIB contained 18 questions, a sample size of 180-360 was required. A sample of 480 participants, who were multi-stage randomly selected, were finally used in testing construct validity. A sample of 50 elderly volunteers living in village No.11 of Khok Kruat sub-district, Mueang district of Nakhon Ratchasima province, were selected for testing inter-rater and intra-rater reliability. An additional 480 elderly volunteers were randomly selected from residents in the Mueang district in the 
same province to test the internal consistency of the tools and construct validity. Data utilized in the construction of the sampling frame for the study sample selection were obtained from the officers of the local Sub-district Health Promoting Hospitals.

\section{Research Tools}

The main data collecting instruments were the Thai SIB version Draft 3 and an additional questionnaire collecting information related to personal demographics, illness information, medication history, life support equipment information, and history of falling. The MMSE-Thai 2002 was also utilized in assessing eligibility relating to the dementia status of the study participants. Furthermore, physical fitness tests including the Time Up and Go (TUG) and Berg Balance Scale (BBS) tests which have high sensitivity and specificity in predicting fall risk in the elderly people were also conducted. ${ }^{11}$

\section{Content Validity Testing}

The SIB Thai version Draft 2 was assessed for the accuracy and content suitability by 5 independent professionals, including a geriatrician, a physician, a nurse specialized in elderly care, a pharmacist, and a physical therapist. Content validity was evaluated by calculating the Index of Item-Objective Congruence (IOC) for every single score obtained from the 5 professionals. The objective accuracy should be 0.5 or greater, as indicated adequate content validity. ${ }^{25,26}$

\section{Test-Retest Reliability and Inter-Rater reliability}

Test-retest reliability was assessed by requesting the 50 study participants to answer the final Thai version of the SIB on two separate occasions, 1 week apart. The consistency between the two sets of data set was subsequently assessed by calculating the Interclass Correlation Coefficient (ICC) using the ICC model $(3,1)$.

The inter-rater reliability between 2 raters (a nurse and a public health technical officer) was conducted by allowing them to independently interview the 50 study subjects using the final SIB Thai version. The consistency between the two data sets was then assessed using an ICC model $(2,2)$. A test-retest reliability and inter-rater reliability ICC value of less than 0.50 indicated poor reliability, $0.50-0.74$ moderate reliability, $0.75-0.90$ good reliability and $>0.9$ excellent reliability. ${ }^{27}$

\section{Construct Validity}

A total of 480 eligible elderly participants were interviewed using the final Thai SIB version. The participants also completed the TUG and BBS tests. The internal consistency was estimated by using inter-item correlations via Kuder-Richardson Formula 21 (KR-21) to compute the coefficient alpha $(\alpha)$. If the coefficient alpha value was $>0.70$ it suggested that the relationship of all the items was good. ${ }^{28}$ The construct validity was then tested by analyzing factors of the evaluation form by applying exploratory factor analysis on the principal component analysis (PCA) and orthogonal rotation by the varimax method. The convergent validity between the Thai SIB version and the TUG and BBS tests was assessed by estimating the correlation coefficient (r) using Pearson's correlation. Statistical significance was set at $p<0.05$. All statistical analyses were performed by using the Statistical Package for the Social Science (SPSS) version 22.0.

\section{Results}

For the test-retest reliability and inter-rater reliability testing, the 50 sampled participants were aged $72.8 \pm 6.64$ yrs (range: $65-90 \mathrm{yrs})$. A total of $52.0 \%$ of the sample were females, $32.0 \%$ were widowed, $74.0 \%$ were elementary school graduated, $60 \%$ did not work, and $12 \%$ lived alone. Approximately one-third $(38.0 \%)$ had a history of at least one previous fall and $20.0 \%$ used a walking aid. Only $16.0 \%$ reported that they were concerned about falling (data not shown).

The 480 sampled participants of construct validity testing were aged $73.3 \pm 6.51 \mathrm{yrs}$ (range: $65-95 \mathrm{yrs}$ ). A total of $52.5 \%$ of the sample were females, $61.5 \%$ were married, $81.5 \%$ were elementary school graduated, and $33.3 \%$ were still employed. Approximately two-thirds $(67.9 \%)$ had at least one chronic illness, $62.1 \%$ did not exercise regularly, 6.5\% lived alone, and $19.8 \%$ used a walking aid such as a cane. Approximately onethird $(32.1 \%)$ had a history of at least one previous fall and $32.5 \%$ were concerned about or feared, falling (Table 1).

\section{Content Validity}

Based on the opinion of 5 professionals, the content validity of the Thai SIB was good, as shown by the IOC range of 0.80-1.00 for its individual question. However, some corrections were made and 6 more questions from an existing local fall assessment tool ${ }^{29}$ were added, as suggested by the professionals, until a third draft of the Thai SIB with 18 questions was finalized. The original and the adapted versions of the Thai SIB were therefore used in further testing. 
Table I Characteristics of the Participants $(n=480)$

\begin{tabular}{|c|c|c|}
\hline Characteristics & $\mathbf{n}$ & (\%) \\
\hline \multicolumn{3}{|l|}{ Gender } \\
\hline Male & 228 & $(47.5)$ \\
\hline Female & 252 & (52.5) \\
\hline \multicolumn{3}{|l|}{ Age (year) } \\
\hline $65-69$ & 178 & $(37.1)$ \\
\hline $70-74$ & 110 & (22.9) \\
\hline $75-79$ & 100 & (20.8) \\
\hline$\geq 80$ & 92 & $(19.2)$ \\
\hline \multicolumn{3}{|l|}{ Civil status } \\
\hline Single & 36 & $(7.5)$ \\
\hline Married & 295 & $(61.5)$ \\
\hline Widowed & 136 & $(28.3)$ \\
\hline Separated & 13 & $(2.7)$ \\
\hline \multicolumn{3}{|l|}{ Living situation } \\
\hline Lives with companion & 449 & (93.5) \\
\hline Living alone & 31 & $(6.5)$ \\
\hline \multicolumn{3}{|l|}{ Education } \\
\hline None & 32 & $(6.7)$ \\
\hline Primary school & 391 & $(81.4)$ \\
\hline Secondary school & 47 & $(9.8)$ \\
\hline Bachelor and above & 10 & $(2.1)$ \\
\hline \multicolumn{3}{|l|}{ Employment status } \\
\hline Did not work & 320 & $(66.7)$ \\
\hline Still working & 160 & (33.3) \\
\hline \multicolumn{3}{|l|}{ Use of assistive device } \\
\hline No & 385 & $(80.2)$ \\
\hline Yes & 95 & $(19.8)$ \\
\hline \multicolumn{3}{|l|}{ Fall history over past I year } \\
\hline No & 326 & $(67.9)$ \\
\hline Yes & 154 & $(32.1)$ \\
\hline \multicolumn{3}{|l|}{ Concern about falling } \\
\hline No & 324 & $(67.5)$ \\
\hline Yes & 156 & $(32.5)$ \\
\hline
\end{tabular}

\section{Test-Retest Reliability}

The two versions of Thai SIB were examined for testretest reliability. The $\operatorname{ICC}_{(3,1)}$ analysis showed that both the original $(0.95, \mathrm{p}<0.001)$ and adapted $(0.91, \mathrm{p}<0.001)$ versions had very good test-retest reliability, respectively.

\section{Inter-Rater Reliability}

The two versions of Thai SIB had a good to very good level of inter-rater reliability. The $\operatorname{ICC}_{(2,2)}$ reliability was slightly higher for the original $(0.92, \mathrm{p}<0.001)$ compared with the adapted $(0.89, \mathrm{p}<0.001)$ version, respectively.

\section{Internal Consistency}

Internal consistency of the Thai SIB showed that the total score for the original $(\alpha=0.78)$ and adapted $(\alpha=0.78)$ versions both had good and comparable levels of internal consistency.

\section{Exploratory Factor Analysis (EFA)}

A correlation matrix was constructed to examine whether each pair of variables differed from zero before proceeding to the EFA for the two versions. The Bartlett's test of sphericity was then applied and showed a Chi-square value of $1464.011(\mathrm{p}<0.001)$ and $1989.772(\mathrm{p}<0.001)$, respectively, indicating significant correlation among the variables and was therefore suitable for factor analysis. In addition, calculation of the Kaiser-Meyer-Olkin measure of sampling adequacy (KMO) showed a value of 0.848 and 0.831 , respectively (value higher than 0.80 was considered as excellent), indicating that a significant proportion of variance in the variables might be caused by common underlying factors. ${ }^{24}$

Principal component analysis (PCA) with varimax rotation was then conducted for both versions of the Thai SIB (Tables 2 and 3). For the original version with 12 questions, Eigenvalues showed that its 12 questions could be divided into 3 factors, of which values ranged of 1.08-3.94 could explain $51.5 \%$ of the total variance (Table 2). Variables and questions in each factor were considered based on factor loadings (relationship between variables and factors) should be 0.40 or greater. ${ }^{24}$ Thus, factor 1 consisted of 5 questions (Items 3, 4, 5, 6, 7) with factor loadings range of $0.676-0.810$ (Table 3 ) related to walking ability, and balancing and body movement. Factor 2 consisted of 3 questions (Items 8, 9, 11) with factor loading range of $0.432-0.730$ related to history of health problems including rushing into the bathroom due to urinary incontinence, feet numbness, and taking sleeping pills. Factor 3 consisted of 3 questions (Items 1, 2, 12) with a factor loading range of $0.642-0.674$ related to fall records, fear of falls, and depression. However, Item 10 did not fit for any factor since its factor loading was less than 0.40 (Table 3).

For the adapted version with 18 questions, 6 factors had eigenvalues greater than 1 , ranging between 1.00 and 4.45 that could explain $59.1 \%$ of the total variance (Table 2). Factor 1 consisted of 5 questions (the same Items as factor 1 of the original version) with a factor loadings range of $0.759-0.776$ (Table 3). Factor 2 
Table 2 Factor, Eigenvalues, Percentage of Variance, and Percentage of Cumulative Variance of the Two Versions Thai Stay Independent Brochure $(n=480)$

\begin{tabular}{|c|c|c|c|c|c|c|c|}
\hline \multicolumn{4}{|c|}{ Thai Stay Independent Brochure-12 Questions } & \multicolumn{4}{|c|}{ Thai Stay Independent Brochure-18 Questions } \\
\hline Factor & Eigenvalue & $\begin{array}{l}\% \text { of } \\
\text { Variance }\end{array}$ & $\begin{array}{l}\% \text { of Cumulative } \\
\text { Variance }\end{array}$ & Factor & Eigenvalue & $\begin{array}{l}\% \text { of } \\
\text { Variance }\end{array}$ & $\begin{array}{l}\% \text { of Cumulative } \\
\text { Variance }\end{array}$ \\
\hline 1 & 3.94 & 32.8 & 32.8 & I & 4.47 & 24.8 & 24.8 \\
\hline 2 & 1.16 & 9.7 & 42.5 & 2 & 1.73 & 9.6 & 34.4 \\
\hline 3 & 1.08 & 9.0 & 51.5 & 3 & 1.22 & 6.8 & 41.5 \\
\hline & & & & 4 & 1.14 & 6.4 & 47.5 \\
\hline & & & & 5 & 1.08 & 6.0 & 53.5 \\
\hline & & & & 6 & 1.00 & 5.6 & 59.1 \\
\hline
\end{tabular}

Table 3 Factor Loading in Each Question of the Two Versions Thai Stay Independent Brochure $(n=480)$

\begin{tabular}{|c|c|c|c|c|c|c|c|c|c|}
\hline \multirow[t]{2}{*}{ Questions } & \multicolumn{3}{|c|}{$\begin{array}{l}\text { Factor Loading of Thai Stay } \\
\text { Independent Brochure-12 } \\
\text { Questions }\end{array}$} & \multicolumn{6}{|c|}{$\begin{array}{l}\text { Factor Loading of Thai Stay Independent Brochure - } 18 \\
\text { Questions }\end{array}$} \\
\hline & Factor I & $\begin{array}{l}\text { Factor } \\
2\end{array}$ & $\begin{array}{l}\text { Factor } \\
3\end{array}$ & $\begin{array}{l}\text { Factor } \\
\text { I }\end{array}$ & $\begin{array}{l}\text { Factor } \\
2\end{array}$ & $\begin{array}{l}\text { Factor } \\
3\end{array}$ & $\begin{array}{l}\text { Factor } \\
4\end{array}$ & $\begin{array}{l}\text { Factor } \\
5\end{array}$ & $\begin{array}{l}\text { Factor } \\
6\end{array}$ \\
\hline I. Fall in the last year & & & 0.659 & & & & & 0.747 & \\
\hline 2. Fear of Falls & & & 0.674 & & 0.574 & & & & \\
\hline 3. Feel unstable while standing/walking & 0.783 & & & 0.761 & & & & & \\
\hline 4. Use walking aids & 0.810 & & & 0.766 & & & & & \\
\hline 5. Hold furniture while walking & 0.740 & & & 0.774 & & & & & \\
\hline 6. Lean on hands while standing up & 0.676 & & & 0.759 & & & & & \\
\hline 7. Difficulty stepping up & 0.731 & & & 0.776 & & & & & \\
\hline 8. Rush to bathroom & & 0.593 & & & & 0.396 & & & \\
\hline 9. Numbness on feet & & 0.730 & & & & 0.733 & & & \\
\hline 10. Feel dizzy, exhausted from taking medication & 0.397 & & & & & & 0.774 & & \\
\hline II. Take sleeping pills, anxiety relieve & & 0.432 & & & & & & & 0.735 \\
\hline 12. Depression & & & 0.642 & & & & & 0.359 & \\
\hline 13. Dizzy while changing posture & & & & & & & 0.693 & & \\
\hline $\begin{array}{l}\text { 14. Feet or knees hurt/pain and not gone in } \\
\text { one day }\end{array}$ & & & & & & 0.692 & & & \\
\hline 15. Admitted to hospital in the last 6 month & & & & & & & & 0.655 & \\
\hline 16. Take many types of medicine, more than 4 & & & & & & & & & 0.620 \\
\hline $\begin{array}{l}\text { 17. Count finger correctly in } 3 \text { meters, at } \\
\text { least } 3 \text { in } 4 \text { times }\end{array}$ & & & & & 0.799 & & & & \\
\hline $\begin{array}{l}\text { 18. Unable to read first page of newspaper in } \\
\text { I foot }\end{array}$ & & & & & 0.662 & & & & \\
\hline Eigenvalues & 3.94 & 1.16 & 1.08 & 4.47 & 1.73 & 1.22 & 1.14 & 1.08 & 1.00 \\
\hline Percent of variance & 32.8 & 9.7 & 9.0 & 24.8 & 9.6 & 6.8 & 6.4 & 6.0 & 5.6 \\
\hline
\end{tabular}


Table 4 The Relationship Between Thai Stay Independent Brochure and Other Falling Risk Evaluating Tools $(n=480)$

\begin{tabular}{|c|c|c|c|c|}
\hline \multirow[t]{2}{*}{$\begin{array}{l}\text { Functional Fitness } \\
\text { Test }\end{array}$} & \multicolumn{2}{|c|}{$\begin{array}{l}\text { Thai Stay } \\
\text { Independent } \\
\text { Brochure-12 } \\
\text { Questions }\end{array}$} & \multicolumn{2}{|c|}{$\begin{array}{l}\text { Thai Stay } \\
\text { Independent } \\
\text { Brochure- I } 8 \\
\text { Questions }\end{array}$} \\
\hline & $r$ & P-value & $r$ & P-value \\
\hline $\begin{array}{l}\text { Time up and go test } \\
\text { Berg balance scale }\end{array}$ & $\begin{array}{l}0.330 \\
-0.499\end{array}$ & $\begin{array}{l}<0.001 \\
<0.001\end{array}$ & $\begin{array}{l}0.358 \\
-0.484\end{array}$ & $\begin{array}{l}<0.001 \\
<0.001\end{array}$ \\
\hline
\end{tabular}

consisted of 3 questions (Items 2, 17, 18) with a factor loading range of $0.574-0.779$ related to vision impairment and fear of falls. Factors 3 to 6 consisted of 2 questions each related to foot or knee pain and feet numbness (Items 9 and 14). Factor 4 was related to dizziness from taking medication and changing postures (Items 10 and 13). Factor 5 was related to fall history and hospital admission in the last 6 months (Items 1 and 15). Finally, factor 6 was related to taking some medications and taking four or more medications (Items 11 and 16). All these 8 question items had a factor loading range of $0.620-0.774$. Unfortunately, Items 8 and 12 did not fit to any factor (Table 3).

Table 4 shows that the convergent validity of Thai SIB with the TUG and BBS was statistically significant. It had positive relationship with the TUG and negative relationship with BBS, since a high TUG score, but low BBS score, relates to increased fall risk.

\section{Discussion}

The objective of the present study was to determine the validity of the Thai SIB as a tool for fall risk screening in elderly Thai individuals. In Thailand, the first stakeholders responsible for screening fall risk are the front-line healthcare personnel, in primary care settings, that do not have specialized training. In this context, the SIB seems to be an appropriate tool as it consists of a short and simple questionnaire to obtain relevant information. Individuals subsequently identified as having a high fall risk can be referred for further assessment by trained personnel using more sophisticated tools, which enable the provision of an individualized fall risk management or fall prevention program.

Our findings showed that the two versions (original version with 12 questions and adapted version with 18 questions) of the Thai SIB had a high applicability when utilized in a Thai community. The SIBs took only 10 mins to administer and participants had no difficulty in completing the tools. Both versions obtained good validity as inferred from the high content validity (IOC: $\sim 0.90$ ), moderate to good uni-dimentionality (factor loadings range of 0.359 to 0.810 ), and confirmed convergent validity with fall-related functional fitness test including TUG and BBS $(r=-0.499$ to 0.358$)$. The SIBs were also shown to be reliable, as demonstrated by the adequate internal consistency ( $\alpha=0.776$ to 0.777 ), which exceeded the minimal recommended value $(\alpha=0.70) .{ }^{28}$ The ICC of the total score of both SIB versions showed excellent test-retest reliability ( 0.912 to 0.954$)$ and good to excellent interrater reliability ( 0.889 to 0.915 ).

Based on our findings, both versions of the Thai SIB had acceptable levels of validity and reliability suggesting that this tool could be used to assess fall risk in an elderly Thai community population. The adapted SIB version, with more questions, provided a better explanation in the variation in falling risk and may therefore be preferred to collect relevant fall risk information. In line with a previous study, ${ }^{30}$ the greater number of risk factors provided an explanation for the greater precision in predicting fall risk (20-30 factors or more). This was our reason for keeping item 10 in original version and items 8 and 12 in adapt version in the Thai SIB even though the principal component factor analysis showing that they might not be well related to any other factor. Nevertheless, consideration about which SIB version should be utilized and which item should be retained when incorporated into a multistep fall risk algorithm should ultimately be based on predictive validity test results. Therefore, despite the extensive validity and reliability parameters undertaken in our study, concurrent and predictive validities should be a focus for future work.

The strength of this study was that each step of translation and cultural adaptation was carefully performed based on standard guidelines, ${ }^{21}$ which was tested in an elderly community population and via various professionals. In addition, the sample sizes were large enough to ensure appropriate statistical power and precision of the results. ${ }^{23,24}$ Importantly, the participants were representative of the broader elderly population in terms of age range, gender and urban-rural areas.

\section{Conclusion}

This study provided evidence that the original and adapted versions of the U.S. SIB is an applicable screening tool in the fall risk assessment algorithm in an elderly Thai 
community population. However, additional evidence on its concurrent and predictive validity is needed before final conclusions can be firmly established.

\section{Acknowledgments}

The authors would like to thank Dr. Chris Mawhinney, College of Sports Science and Technology, Mahidol University, for his grammatical corrections and his valuable suggestion. Additionally, we would like to thank the professionals who provided valuable opinions on the process of translation and adaptation.

\section{Funding}

This study was supported by a research grant from Ratchadapiseksompotch Fund, Faculty of Medicine, Chulalongkorn University, fiscal year 2019, grant number RA62/024 and the 90th Anniversary of Chulalongkorn University Fund (Ratchadaphiseksomphot Endowment Fund), grant number GCUGR1125622041D.

\section{Disclosure}

The authors have no conflicts of interest to declare.

\section{References}

1. World Health Organization. WHO Global report on Falls prevention in older age; 2019 [cited February 4, 2019]. Available from: https://www. who.int/ageing/publications/Falls_prevention7March.pdf?ua=1. Accessed December 5, 2019.

2. Ken ny RA, Romero-Ortuno R, Kumar P. Falls in older adults. Medicine. 2017;45(1):28-33. doi:10.1016/j.mpmed.2016.10.007

3. World Health Organization. Falls [Internet]. 2019. [cited February 24 , 2019]. Available from: https://www.who.int/news-room/fact-sheets /detail/falls. Accesssed December 2, 2019.

4. Bureau of Non Communicable Diseases, Department of Disease Control. Annual Report 2018. Bangkok, Thailand: Aksorn and Graphic design company limited; 2018.

5. Romli MH, Tan MP, Mackenzie L, Lovarini M, Suttanon P, Clemson L. Falls amongst older people in Southeast Asia: a scoping review. Public Health. 2017;145:96-112. doi:10.1016/j. puhe.2016.12.035

6. Ham RJ, Sloane PD, Warshaw GA, Potter JF, Flanerty E. Ham 's Primary Care Geriatrics: A Case-Based Approach. 6th ed. Mosby; 2014.

7. Halter JB, Ouslander JG, Studenski S, et al. Hazzard's Geriatric Midicine and Gerontology. 7th. New York: Mc Graw Hill Education; 2017.

8. Gillespie LD, Robertson MC, Gillespie WJ, et al. Interventions of preventing falls in older people living in the community. Cochrane Database Syst Rev. 2012;9:CD007146. doi:10.1002/14651858. CD007146.pub3

9. Lusardi MM, Fritz S, Middleton A, et al. Determining risk of falls in community dwelling older adults: a systematic review and meta-analysis using posttest probability. $J$ Geriatr Phys Ther. 2017;40(1):1-36. doi:10.1519/JPT.0000000000000099
10. Gates S, Smith LA, Fisher JD, Lamb SE. Systematic review of accuracy of screening instruments for predicting fall risk among independently living older adults. J Rehabil Res Dev. 2008; 45:1105-1116. doi:10.1682/JRRD.2008.04.0057

11. Park SH. Tools for assessing fall risk in the elderly: a systematic review and meta-analysis. Aging Clin Exp Res. 2017;30(1):1-16.

12. Obrist S, Rogan S, Hilfiker R. Development and evaluation of an online fall-risk questionnaire for nonfrail community-dwelling elderly persons: a pilot study. Curr Gerontol Geriatr Res. 2016;2016:1-16. doi:10.1155/2016/1520932

13. Centers for Disease Control and Prevention (CDC). Resource: algorithm for fall risk screening, assessment, and intervention [Internet]. 2018. [cited February 4, 2019]. Available from: https://www.cdc.gov/ steadi/pdf/STEADI-Algorithm-print.pdf. Accesssed December 2, 2019.

14. Phelan EA, Mahoney JE, Voit JC, Stevens JA. Assessment and management of fall risk in primary care settings. Med Clin North Am. 2015;99(2):281-293. doi:10.1016/j.mena.2014.11.004

15. American Geriatrics Society and British Geriatrics Society. Summary of the updated American geriatrics society/British geriatrics society clinical practice guideline for prevention of falls in older persons. $J \mathrm{Am}$ Geriatr Soc. 2011;59(1):148-157. doi:10.1111/jgs.2011.59.issue-1

16. Vivrette RL, Rubenstein LZ, Martin JM, Josephson KR, Kramer BJ. Development of a fall-risk self-assessment for community-dwelling seniors. J Aging Phys Act. 2011;19(1):16-29. doi:10.1123/ japa.19.1.16

17. Deandrea S, Lucenteforte E, Bravi F, Foschi R, La Vecchia C, Negri E. Risk factors for falls in community-dwelling older people: a systematic review and meta-analysis. Epidemiology. 2010;21 (5):658-668. doi:10.1097/EDE.0b013e3181e89905

18. Rubenstein LZ, Vivrette R, Harker JO, Stevens JA, Kramer BJ. Validating an evidence-based, self-rated fall risk questionnaire (FRQ) for older adults. J Safety Res. 2011;42(6):493-499. doi:10.1016/j.jsr.2011.08.006

19. Lohman MC, Crow RS, DiMilia PR, Nicklett EJ, Bruce ML, Batsis JA. Operationalisation and validation of the Stopping Elderly Accidents, Deaths, and Injuries (STEADI) fall risk algorithm in a nationally representative sample. J Epidemiol Community Health. 2017;71(12):1191-1197. doi:10.1136/jech-2017-209769

20. McKechnie D, Pryor J, Fisher MJ. Predicting falls: considerations for screening tool selection vs. screening tool development. $J$ Adv Nurs. 2016;72(9):2238-2250. doi:10.1111/jan.12977

21. Beaton DE, Bombardier C, Guillemin F, Ferraz MB. Guideline for the process of cross-cultural adaptation of self-report measures. Spine. 2000;25:3186-3191. doi:10.1097/00007632-200012150-00014

22. Prasat Neurological Institute, Department of Medical Services. Clinical Practice Guidelines: Dementia. 1st ed. Bangkok: Tanapress Company Limited; 2014.

23. Terwee CB, Mokkink LB, Knol DL, Ostelo RW, Bouter LM, de Vet HC. Rating the methodological quality in systematic reviews of studies on measurement properties: a scoring system for the COSMIN checklist. Qual Life Res. 2012;21(4):651-657. doi:10. 1007/s11136-011-9960-1

24. Jr JFH, Black WC, Babin BJ, Anderson RE. Multivariate Data Analysis. 7th ed. Edinburgh: Pearson; 2014.

25. Rovinelli RJ, Hambleton RK. On the use of content specialists in the assessment of criterion-referenced test item validity [Internet]. 2019 [cited February 4, 2019]. Available from: https://files.eric.ed.gov/full text/ED121845.pdf. Accesssed December 2, 2019.

26. Dhippayom JP, Trevittaya P, Cheng ASK. Cross-cultural adaptation, validity, and reliability of the patient-rated michigan hand outcomes questionnaire for Thai patients. Occup Ther Int. 2018;2018:1-6. doi: $10.1155 / 2018 / 8319875$ 
27. Koo TK, Li MY. A guideline of selecting and reporting intraclass correlation coefficients for reliability research. J Chiropr Med. 2016;15(2):155-163. doi:10.1016/j.jcm.2016.02.012

28. Terwee CB, Bot SDM, de Boer MR, et al. Quality criteria were proposed for measurement properties of health status questionnaires. J Clin Epidemiol. 2007;60(1):34-42. doi:10.1016/j. jclinepi.2006.03.012
29. Thiamwong L, Thamarpirat J, Maneesriwongkul W, Jitapunkul S. Thai falls risk assessment test (Thai-FRAT) developed for community-dwelling Thai elderly. J Med Assoc Thai. 2008;91:18 23-1832.

30. Palumbo P, Palmerini L, Bandinelli S, Chiari L. Fall risk assessment tools for elderly living in the community: can we do better? PLoS One. 2015;10(12):e0146247. doi:10.1371/journal.pone.0146247

\section{Publish your work in this journal}

Clinical Interventions in Aging is an international, peer-reviewed journal focusing on evidence-based reports on the value or lack thereof of treatments intended to prevent or delay the onset of maladaptive correlates of aging in human beings. This journal is indexed on PubMed Central, MedLine, CAS, Scopus and the Elsevier
Bibliographic databases. The manuscript management system is completely online and includes a very quick and fair peer-review system, which is all easy to use. Visit http://www.dovepress.com/ testimonials.php to read real quotes from published authors. 